\title{
Research on the Application of Cultural and Creative Products Based on the Pattern Design of Qiang Culture
}

\author{
Lijuan Xiong, ${ }^{1, *}$
}

\author{
${ }^{1}$ School of Fine Arts and Design, Chengdu University, Chengdu, Sichuan, China \\ *Corresponding author. Email: xiongxiong_1980@yeah.net
}

\begin{abstract}
This research, based on the research on the pattern design method of Qiang ethnic minority, explores the development and application of cultural and creative products with graphic patterns in Qiang area as the focus. The concept of international vision is combined to enhance the sense of design and the internationalization of cultural and creative products in the Qiang area. Through combing the representative themes of the Qiang ethnic minority, especially the Qiang embroidery patterns, the research redesigns the products and starts from the four aspects of pattern composition, style integration, handicraft integration, and day-selling product design to explore the thoughts and methods of development and design of cultural and creative products in Qiang area and design products that not only conform to modern young consumers' aesthetics and habits of using products, but also contain typical cultural characteristics of Qiang ethnic minority.
\end{abstract}

\section{Keywords: Qiang ethnic minority, cultural symbols, product design, innovative design, tourist souvenirs}

\section{INTRODUCTION}

The Qiang ethnic minority is an ancient ethnic group between Han and Tibetan Ethnic. The Wenchuan earthquake in 2008 hit the Qiang area hard. In the ten years after the earthquake, governments at all level increased the construction and development of the Qiang area in order to build up the national selfconfidence of the Qiang people, vigorously promote Qiang culture, develop Qiang tourism, and promote economic development in the Qiang areas. This paper starts from the ethnic group's representative themes, especially its embroidery patterns to probe the ideas and methods of the creative design of its cultural and creative products. After the investigation of the current situation of its cultural and creative products, it is found that although the Qiang's product categories are relatively rich, but under the conditions of market economy and rapid production of large-scale industries, the ethnic group's cultural and creative product design shows insufficient product development analysis, lagging design style and other phenomena in the current stage.

\section{A. Insufficient analysis of product development needs}

At present, the development of Qiang embroidery cultural products focuses on traditional handicrafts with the consideration of production cost and price that is not cheap. The more popular Qiang embroidery products and tourist souvenirs are mainly concentrated in small accessories such as Qiang embroidered sachets and card bags, whose prices are usually around 100-500 yuan. Ordinary people accustomed to the mechanical manufacturing environment can hardly imagine that a cotton-embroidered pillow coat needs to be sold for nearly 1,000 yuan. There are no markets for the highend Qiang embroidery products marked price in Qiang embroidery specialty stores.

\section{B. Lagging design style}

At present, the development and design of cultural and creative products cannot be well linked with the market. They are still mainly produced in accordance with traditional styles, which cannot meet the aesthetic needs of young consumer groups. This lagging style not only affects tourists, but also affects the cultural identity of the Qiang ethnic minority.

For tourists, what they see in the scenic spot isn' t only a small part of products full of the Qiang's characteristics, but more products produced by large machinery industries and products printed with "someone's memorial" in the 60s and 70s style.

For the Qiang people, the Qiang embroidery patterns are not only the pictorial history of the formation of the ethnic group, but also the iconography of its belief and spiritual sustenance. Under the circumstances of machine manufacturing, changes in the lifestyle and consumption concepts of Qiang ethnic minority have reduced the Qiang people's demands for Qiang hand-embroidered products. This has further led 
to the new generation of Qiang youths knowing little about the meaning of Qiang patterns.

Combining the above two factors, the development thinking of the Qiang's cultural and creative products has tried to change from a single traditional handicraft development to an innovative design development and application emphasizing Qiang embroidered pattern. So as to design the products that not only conform to the aesthetic and usage habits of modern young consumers, but also contain the typical Qiang cultural characteristics.

\section{SELECTION OF THEMES FOR THE DEVELOPMENT OF QIANG ETHNIC MINORITY'S CULTURAL AND CREATIVE PRODUCTS}

The folk ornaments of the Qiang ethnic group have their specific cultural and graphic styles. The source of Qiang embroidery pattern theme can be divided into four categories. The first type of the embroidery pattern theme comes from Qiang legends (remote antiquity, ancient times), Qiang myths, Qiang epics, folk stories (fantasy, life, fables, jokes) and so on, and patterns evolving from mythical stories and represented by azaleas, polyurethane, chrysolophus and mythical animals. The second type of the embroidery pattern theme comes from religious activities. The eight auspicious treasures and 10,000-character lattices embroidered on the clothes of Qiang women are all influenced by Buddhist culture. The third type is produced from the living environment of the Qiang people, including the embroidery of landscapes, plants, animals, architecture, and living utensils. Effected by ethnic customs, the fourth type includes mainly scene life, singing and dancing (Shalang, Zhuanzhuanhua), labor, and paper cutting patterns, etc. [1]. These patterns are derived from the Qiang ethnic minority's religion, mythology, folklore, the Qiang people's daily life and supplies, and the Qiang's language pronunciation, which provides rich original materials for the development of the Qiang's cultural and creative products.

These graphics carrying the traditional culture of the nation are based on the consensus of people. Representative, distinctive and well-known graphics with local favor and specific meanings can arouse people's visual and perceptual resonance of thought. For design exploration, the author selects several patterns with Qiang cultural characteristics from Qiang embroidery patterns which are the representative of Qiang totem--horn-like pouch, the representative of Qiang's religious beliefs--white stone fir branch embroidery and the representative of Qiang embroidery - apron horn-like flower embroidery, and also adds the daily words of the Qiang-greetings. These themes can be seen everywhere in the Qiang area with a high degree of recognition and ethnic cultural characteristics.

\section{ANALYSIS OF THE DESIGN IDEAS AND METHODS OF THE QIANG'S CULTURAL AND CREATIVE PRODUCTS}

The design ideas of the Qiang's cultural and creative products takes hold in the excavation of cultural elements with the Qiang ethnic minority's characteristics. For the problems of lack of in-depth exploration of consumers' needs and relatively single development of cultural products in the current design of cultural and creative products of Qiang ethnic group, Qiang's decorative patterns are combined with modern composition methods, different design styles are incorporated to allow traditional craftsmanship to be displayed ingeniously, and an explorative design is conducted from four aspects of the development of the Qiang language's elements. The research strives to integrate the Qiang culture into the lives of people in the new era. Only by integrating the Qiang culture into life culture can it be passed on.

\section{A. Simplification, abstraction, decomposition and reorganization of pattern composition}

Xun Shenglan summarized the design of the basic shape, which originated from the simplification and decomposition of the shape [2]. There are different expressions about simplification. The purpose of simplification is to seek truth and remove appearance. Simplification to the extreme is abstraction. The compositional method of combining basic elements in modern plane composition with basic shapes is used. The representative ethnic figures are simplified in different degrees to accord with composition and then form a new basic form to complete the preliminary extraction and application of the basic shape of the ethnic tradition. Decomposition helps to understand the original systemic relationship between "aggregation" and "combination" of basic shapes by refining the constituent elements. Designers can use broken relationship links and combine new links to create new graphics.

The design method of decomposition and reconstruction is combined with the pattern creation shape of "White Stone Fir Branch" in the embroidery technique of the foot border in the Qiang costume. First of all, try to construct the graphic combination method, and use the method of intersecting and blending the two prototypes to extract "A Ge (brother)" and "A Mei (sister)". Second, arrange the prototype to use the number of 7 that represents the Qiang gods and form the shape as "Big Guy" ("Fig. 1"). The "Big Guy" graphic is used in the packaging design of cultural and creative products ("Fig. 2"). 


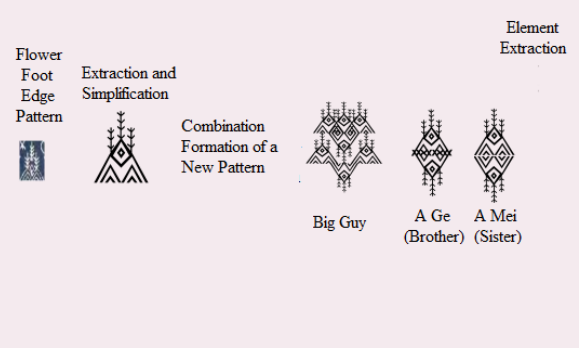

Fig. 1. Shape change of "white stone fir branch" pattern on the flower foot edge.

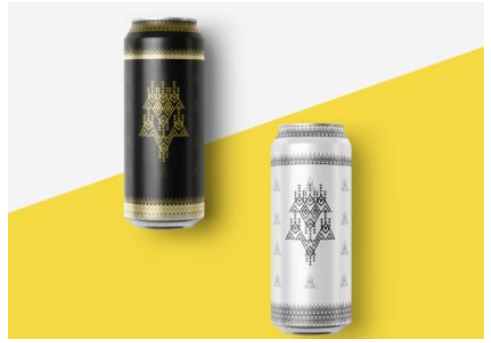

Fig. 2. Packaging design of cultural products.

\section{B. Style fusion of pattern composition}

1) The fusion of Qiang embroidered pattern and Han culture: The expression of meaning and the creation of artistic conception in Han culture is mainly made on the poetic creation of scenes. Meaning comes from the creator's depiction of the scenery. The most direct expression of the artistic conception of the situation is through traditional Chinese paintings, especially the traditional Chinese painting style represented by the Song Dynasty's flower and bird paintings. Methods such as broken branch, intercepting and whitening are used to create an artistic conception [3].

Regarding the broken branch composition method, Sun Qifeng commented on the composition of branches in his book Techniques of Chinese Flower and Bird Painting as follows: "The broken branch composition, by intercepting the angle in part of flowers and birds in nature, creates a broad space that is constantly deepened by the association. [4]" Flower and bird painting creates an artistic conception through the broken branches. The Qiang embroidery pattern ("Fig. 3 ") is combined with the composition method of broken branches ("Fig. 4") to form a new figure with Chinese artistic conception ("Fig. 5").

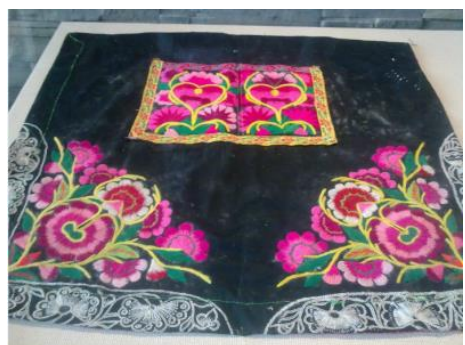

Fig. 3. Exhibits of Beichuan Qiang Folk Museum.

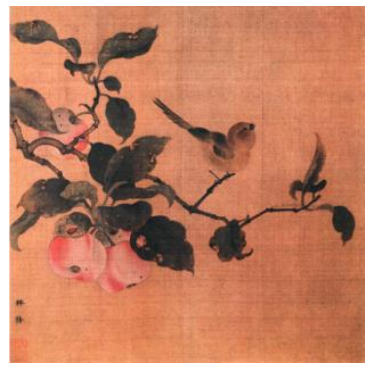

Fig. 4. Song Dynasty's flower and bird painting of broken branches.

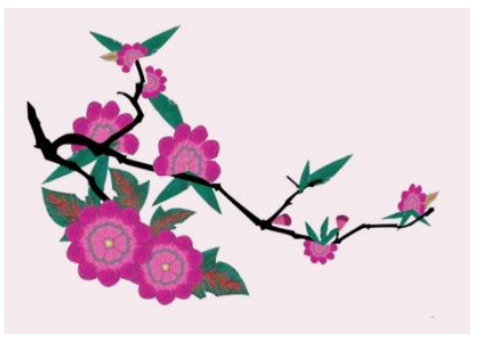

Fig. 5. Chinese style patterns with Qiang elements.

2) The fusion of Qiang embroidered patterns and modern art style: The expression of artistic conception is sought from the traditional oriental style and more diverse forms in the western art style were pursued. "Modernist art originated from Impressionism and PostImpressionism in the 19th century. Its ancestor was Cézanne. Later Fauvism, Cubism, Expressionism, Dadaism and Surrealism belong to modernist art[5]. The establishment of the Bauhaus education system under the influence of Russian Constructivism and the Dutch style school opened the curtain for modern design art [6]. From the impressionists who pursue objective color changes to the Fauvists who seek selfcolor experience, from the Cubism with multidimensional space's graphic expression, the Dadaism denying everything to the Surrealism creative with selfintention. The modern art style is manifested in individualistic denial of self-identification. More and more young people are looking for the presence of themselves in modern art.

The shape of the horn-like sachet in the horn-like pouch of the stockade village named Radish ("Fig. 6") is refined and simplified, and a new pattern is formed 
by using the grouping method in the composition. Choose the color matching of "Marilyn Monroe" made by pop art master Andy Warhol from many modernist design schools to complete the graphic design ("Fig. 7"). Combine modern dress styles for T-shirt design ("Fig. 8").

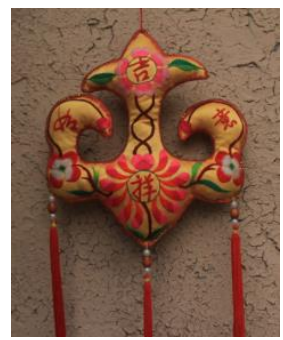

Fig. 6. Qiang horn-like sachet of radish stockade village.

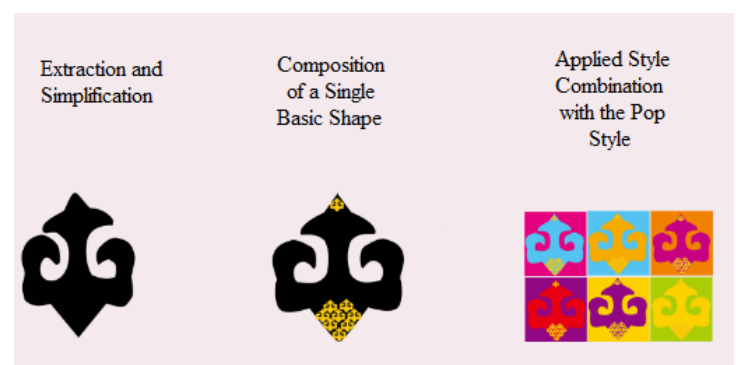

Fig. 7. Evolution of the pop art expression of the "horn-like pouch".

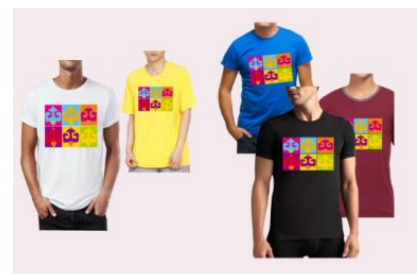

Fig. 8. T-shirt design of the Qiang culture.

3) The fusion of modern and classical styles: In addition to the fusions of Chinese and Western styles mentioned above, the author explores the third waycombining modern and classical styles. Combining the modernist Memphis style design with the broken branch pattern of the horn flower to form a new graphic style applied into the design of mobile phone cases commonly used by modern people ("Fig. 9").

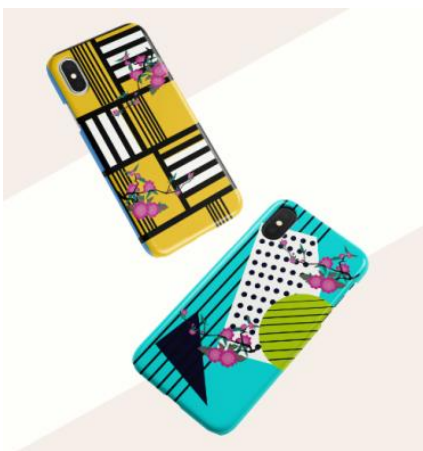

Fig. 9. Memphis-style mobile phone case design with Qiang characteristics.

\section{Ingenious integration of intangible cultural heritage}

The pillow pattern is formed from the combination of the pattern of the corner design of the Qiang apron and the simple Chinese style of broken branches with the flat embroidery stitching method, also known as "plain stitch embroidery" which is also called "zhahua" by Qiang women. The main point of this kind of embroidery is to keep the stitches fine and flat. It is a kind of embroidery stitch that is easy to use. Process patterns by combining transfer with embroidery. On the one hand, there is more space for the design of patterns; on the other hand, it also adapts to the modern fastpaced society, reducing the time for consumers to make embroidery later. Consumers directly become product finishers, which not only gives consumers a sense of accomplishment in production, but also makes products have good interactivity. At the same time, Qiang intangible cultural heritage is allowed to be truly integrated into daily life. ("Fig. 10", "Fig. 11")

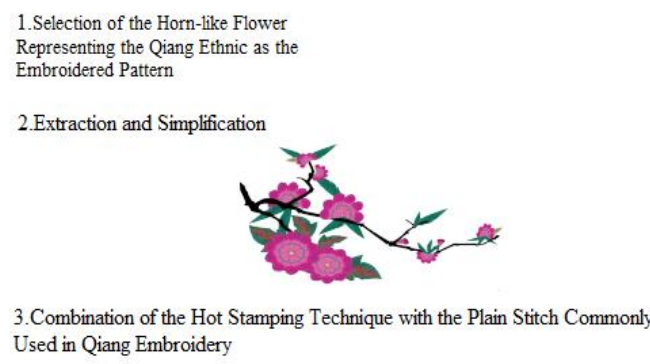

Fig. 10. Embroidered pattern of the Qiang horn-like flower.

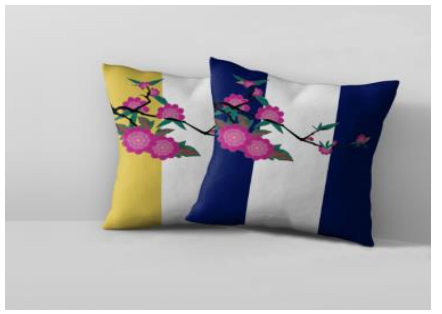

Fig. 11. The pillow design embroidered pattern of the Qiang horn-like flower. 


\section{Applicative development of Qiang language}

As we all know, due to the ethnic changes of the Qiang people, the Qiang people have no characters, but they have their own unique pronunciation. "Qiang language, one used by the Qiang people in our country, is a core language in the Qiang branch of the TibetoBurman family of the Sino-Tibetan language family, belonging to the northern branch of the Qiang language family. Qiang language retains many ancient features of the Tibet-Burman language family, which has become a unique element of the Qiang Nationality. [7]" At present, designers are more concerned with the excavation and application of the nationality's embroidered patterns rather than the development of Qiang language. The author tries to incorporate the pronunciation of Qiang language into its design of daily necessities.

"Na ji na lu" in the Qiang language pronunciation is a kind of blessing language of the Qiang Nationality similar to the meanings of "Ji xiang ru yi" in Chinese and "Good luck and happiness to you" in English. This kind of blessing language used in the design of tourist souvenirs not only expresses good wishes, but also has distinctive Qiang characteristics and can effectively spread Qiang culture. Designing from the perspective of cultural phonetics is also an attempt at a new design direction ("Fig. 12").

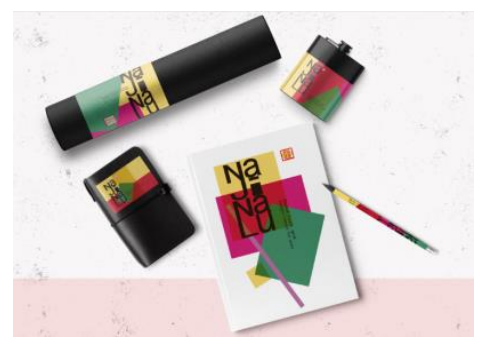

Fig. 12. Cultural and creative products - stationery design.

\section{Conclusion}

The Qiang's cultural and creative products not only needs to be developed regionally and culturally, but also needs to be designed specifically for the target group. The research only explores the possibility of designing a Qiang pattern design that meets the aesthetics of young people from four aspects: pattern composition, style combination, handicraft combination, and Qiang culture excavation, and applies graphics to the design and development of the Qiang's cultural and creative products. The development of cultural and creative products can not only bring new economic benefits to the Qiang area, but also allow Qiang culture to penetrate into the lives of modern Qiang people, which is of great significance to the inheritance of Qiang culture.

\section{Acknowledgment}

This research was financially supported by the key research base of Humanities and social sciences of Sichuan Education Department-Research Center of overall urban and rural education development in 2020 (Grant No. TCCXJY-2020-D43), the General Project of Sichuan Provincial Department of Education (Grant No. 18SB0148).

\section{References}

[1] Y. Z. Jia, An Introduction to the Intangible Cultural Heritage of Qiang Nationality in China. Beijing: Nationalities Publishing House. 2010, pp.7-13.

[2] S. L. Xun, W. L. Peng, New folk art design. Beijing: Peking University Press. 2013, pp.2.

[3] X. J. Zhao, "The artistic conception of flower and bird paintings with broken branches in Song Dynasty," Science Times, vol. 2015, pp. 321-321, January, 2015.

[4] Q. F. Sun, Techniques of Chinese Flower and Bird Painting, Beijing: People's Fine Arts Publishing House. 2008, pp.63.

[5] X. H. Luo, "Research on the teaching content of modern art and modern design history," Hundred Schools in Arts, vol. 2009, pp. 285-286, December, 2009.

[6] J. F. Ye, "On the emergence and influence of Bauhaus," Journal of Jiujiang Unversity (Social Science Edition), vol. 28, pp.6264, June, 2009

[7] H. K. Sun, G. K. Liu, "A survey of Qiang language," Journal of Aba Teachers College, vol. 2014, pp. 5-12, September, 2014. 